Reportagem

\title{
Sonia Ospina apresenta avaliação e resultados da gestão pública na América Latina
}

Dominique Ferreira Feliciano de Lima

A Escola Nacional de Administração Pública (ENAP) recebeu, em nove de agosto deste ano, a professora e pesquisadora Sonia Ospina Bozzi da Universidade Estadual de Nova York, nos Estados Unidos. A pesquisadora colombiana esteve na escola para ministrar a aula inaugural do Curso Internacional sobre Avaliação de Programas Sociais promovido pela Escola Ibero-americana de Administração e Políticas Públicas (EIAPP) do Centro Latino-americano para o Desenvolvimento (Clad) e pela ENAP, do qual participaram 30 dirigentes públicos de áreas sociais de 13 países da América Latina.

Sonia Ospina é doutora em Sociologia pela Universidade Estadual de Nova York e professora associada de Gestão Pública na Universidade de Nova York (NYU). É

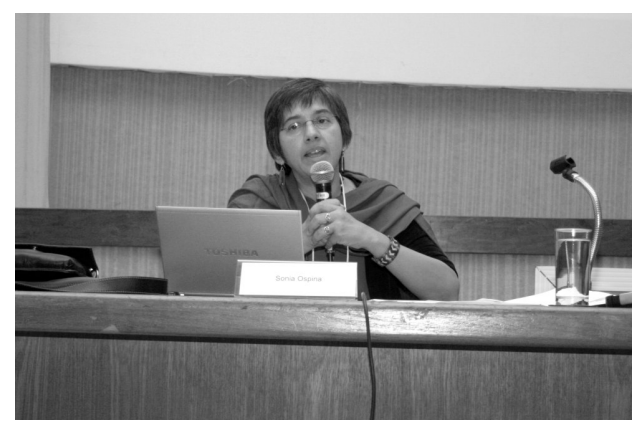

Sonia Ospina Bozzi - professora e pesquisadora da Universidade Estadual de Nova York, nos Estados Unidos. diretora acadêmica do Centro de Pesquisa para Liderança em Ação, que desenvolve estudo sobre liderança, câmbios sociais, gestão pública e governança na América Latina. Suas publicações incluem livros e artigos em revistas acadêmicas sobre os temas gestão e avaliação de políticas públicas, segundo site do Clad.

A exposição intitulada "A evolução dos resultados da gestão pública na América Latina: grandes temas e desafios" buscou traçar um mapa cognitivo sobre temas, tendências e desafios relacionados com o assunto de avaliação e monitoramento na América Latina. Este texto traz uma síntese dos temas levantados pela pesquisadora em sua aula inaugural.

\section{Estado e gestão pública na América Latina}

Sonia Ospina iniciou sua apresentação citando Bresser-Pereira, refinado analista da administração pública na América Latina, quando fala da importância da melhora na capacidade de gestão do Estado: Para ele, "A reconstrução da capacidade estatal é uma condição essencial para que os países latino-americanos enfrentem de forma mais exitosa os problemas $\mathrm{da}$ redemocratização, do desenvolvimento econômico e da distribuição da riqueza. Nesse contexto, a implementação da 
reforma gerencial é um aspecto fundamental para melhorar a capacidade de gestão do Estado, assim como para aumentar a governabilidade democrática do sistema político".

A fala de Bresser-Pereira, proferida em 1998 num discurso para o Centro Latinoamericano de Administração para o Desenvolvimento (Clad) durante curso sobre o papel e a capacidade do Estado, marcou a fase de reconsideração sobre a importância do Estado ao longo das décadas de 1980 e 1990.

Para Sonia, antes se apontavam os problemas como oriundos todos do Estado. Após o consenso de Washington, foram oferecidos parâmetros para privatizar, cortar e contratar. Essas medidas redirecionaram as ações do Estado, retirando-lhe capacidade para investir em atividades produtivas e sociais. Para Bresser-Pereira, no entanto, esse quadro era um desastre, pois o Estado é necessário. Não um Estado grande e pesado, mas um Estado enxuto e capaz. "Se a única maneira de as instituições democráticas funcionarem é com um Estado capaz, então é importante que nós possamos conduzir uma reforma estrutural na América Latina", disse.

A organização da coisa pública é importante para considerar-se uma nova abordagem da governança, aplicada no início do século 21. É um movimento global de reforma que ocorre em todos os lugares. A passagem da noção de gestão pública para a visão de sistema público não é somente um jogo de palavras, segundo Ospina. Ela enumera cinco perguntas que se colocam e começam a influenciar a forma como os gestores pensam a questão.

1. Como podemos produzir mais?

2. Como usar os incentivos de mercado e orientar a burocracia tradicional para as ações sociais?
3. Como o Governo pode conectarse de novo com os cidadãos para oferecer serviços efetivos e de qualidade?

4. Como o Governo pode criar programas e aperfeiçoá-los para que respondam às necessidades locais de maneira mais efetiva? Como descentralizar esses processos?

5. O que pode o Governo fazer para cumprir as promessas? Essa é uma questão de prestação de contas ou de responsabilização.

Em relação à primeira pergunta, Sonia Ospina destaca que a abordagem deve englobar não só como o Estado pode produzir mais serviços com menos recursos, mas também como se pode fazê-lo sem descuidar das estratégias de efetividade e eficiência para o desenvolvimento. "Com isso voltamos a uma perspectiva mais humana", explicou.

A segunda questão também se aprofunda para a pesquisadora e suscita mais questões: Como é possível trabalhar com o mercado e a sociedade civil para abordar de maneira conjunta os problemas coletivos e superar dificuldades? Os três setores trabalhando juntos são o novo modelo de governança? Como pode o Governo se conectar melhor com os cidadãos para prover esses serviços? O que devemos fazer para que os cidadãos também participem dessa discussão?

A quarta questão trata da efetividade de programas e da descentralização. No entanto, lembra a pesquisadora, para que a descentralização tenha sentido é preciso responsabilidade. Por vezes, problemas surgem por causa de uma descentralização irresponsável, o que compromete a efetividade de qualquer programa.

Por último, a prestação de contas se mantém como uma questão em evolução para todos os modelos de gestão, diz Sonia Ospina. De certo modo, a ideia de 
colaboração superou a do trabalho individualizado, que existe dentro e fora do setor público. A liderança colaborativa passou a ser o valor defendido, superando a liderança individual.

Nesta década a ênfase está no valor público: "Esta é uma mudança significativa com relação à ideia que tínhamos nas décadas de 1980 e 1990. Significa uma nova visão de gestão pública. Já falamos de um gerente que não é neutro, mas, sim, político”. A professora citou Leonardo Guarnieri, que foi ministro do Planejamento na Costa Rica e um dos introdutores do sistema de avaliação no país, para relembrar que o desenho da política pública é um exercício coletivo e democrático.

"Trata-se de um tema predominantemente político porque ao se fazer política pública define-se quais as prioridades almejadas pela sociedade. Sendo assim, o gerente tem o papel fundamental de garantir que as políticas criem valor público ao serem implementadas, para que as prioridades decididas no nível coletivo se transformem em realidade", definiu.

O gerente não é neutro. Não se quer que ele seja menos político como a nova gestão pública (New Public Management) pretendia. O objetivo é que ele tenha maior capacidade política no melhor sentido da palavra, segundo a pesquisadora. A designação de recursos públicos é fundamentalmente uma tarefa política. A visão geral da nova administração pública é a de que o gerente deve ser capaz de motivar os líderes da organização, para que todos cooperem para a concretização dos interesses públicos. Ele tem que trabalhar em diálogo com os técnicos e com os atores políticos.

Sonia Ospina destaca que esse é um novo enfoque conceitual, que de imediato nos leva a uma orientação para os resultados das ações conduzidas pelo Governo.
A preocupação fundamental do gerente precisa ser produzir valor público. $\mathrm{E}$ a gestão por resultados seria a melhor forma de assegurar o conhecimento para corrigir o rumo à medida que se avança, para que se saiba no final se os objetivos foram atingidos.

\section{Monitoramento e avaliação no setor público}

A avaliação e a orientação por resultados são questões-chave para a pesquisadora. Inclusive, em avaliações ex-ante ou de processos, o olhar é orientado para o resultado. Essa visão importa porque estabelece a estrutura de motivação. Embora na aula inaugural ela tenha tratado avaliação e monitoramento como se significassem o mesmo para facilitar sua exposição, ao iniciar sua argumentação lembrou a todos que eram conceitos diferentes, apresentando para ambos os conceitos motivações diferenciadas, expressas de forma sintética no Quadro 1.

\section{Quadro 1:}

Avaliação:

- Valoração pontual e abrangente

- Usada para explicar processos e/ou resultados

Monitoramento:

- Valoração periódica e parcial

- Usado para dar seguimento a processos, produtos e resultados.

A pesquisadora destacou a partir desse quadro que o uso da palavra resultados pode criar confusão. Os resultados dizem respeito aos da intervenção pública, mas algumas vezes são interpretados erroneamente como os resultados da avaliação.

Isso porque o monitoramento e a avaliação dos resultados são ferramentas de uma gestão para resultados, que estão 
Quadro 2 - Gestão para resultados: uma mudança cultural

\begin{tabular}{|c|c|c|}
\hline Insumos & Visão/Missão & \\
\hline $\begin{array}{l}\text { Autorização } \\
\text { Recursos humanos } \\
\text { Tecnologias \& } \\
\text { informação } \\
\text { Recursos financeiros }\end{array}$ & $\begin{array}{l}\text { Processos de produ- } \\
\text { ção e prestação de serviços } \\
\text { (sistemas de gestão) }\end{array}$ & $\begin{array}{l}\text { Serviços \& produtos - } \\
\text { resultados (mudança) }\end{array}$ \\
\hline $\begin{array}{l}\text { Critérios de } \\
\text { avaliação: }\end{array}$ & & \\
\hline Legalidade/Equidade & $\begin{array}{l}\text { Eficiência/Economia } \\
\text { Responsividade } \\
\text { Legitimidade } \\
\text { Transparência }\end{array}$ & $\begin{array}{l}\text { Efetividade } \\
\text { Qualidade/Impacto }\end{array}$ \\
\hline
\end{tabular}

inseridos na ideia da mudança da cultura de gestão para revisão do trabalho de maneira diferente. "O conceito pode soar óbvio, mas no contexto da administração é uma ideia nova", disse.

Para entendê-lo um pouco melhor, considerando-se as três caixas presentes no Quadro 2 como sistemas de produção com insumos, processos e produtos para obtenção de um resultado concreto, podese ver a mudança na ênfase dos critérios de avaliação.

$\mathrm{Na}$ visão tradicional da administração pública o que se enfatiza são os problemas dos recursos públicos. Em consequência, o gerente e o sistema têm permanecido focados na maneira de assegurar legalidade para as ações e garantir que os insumos sejam bem administrados, em detrimento de fazer que as ações preparadas com insumos predeterminados produzam resultados concretos e efetivos para o cidadão.

Este foco na área de recursos tem implicações para os critérios de avaliação que dizem respeito a insumos e processos. "Numa sociedade baseada no Estado de direito é fundamental dar atenção à igualdade e à eficiência. Nós esquecemos a efetividade e a qualidade do impacto porque estamos orientando a reação em que os principais usuários dos serviços são os próprios funcionários. Isso porque eles passariam a organizar as atividades para se protegerem. A ideia da orientação para os resultados é dizer que é necessário expandir, transformar o sistema para se tornar aberto", explicou.

Se a ênfase for neste tipo de resultado e não apenas em seu aspecto financeiro, esses produzem uma energia que nos leva ao próximo passo. Eles criam novas capacidades, que possibilitam novos resultados. Quando o enfoque está no que se quer, usa-se a informação para ajustar o caminho ao fim, com inovação e criatividade. Se a informação é mal utiliza$\mathrm{da}$, redunda apenas em uma cultura de medo, de castigo e de culpas. Ou seja, é 
preciso pensar como o trabalho pode ser feito para alcançar bons resultados, de forma que o enfoque não seja apenas orientado para penalizar ou castigar o servidor público, ponderou a pesquisadora.

O ponto-chave para Ospina é como o monitoramento, a avaliação e a estrutura de resultados se relacionam com os arcabouços de desenvolvimento, que são os programas sociais e as aspirações coletivas. O maior trabalho é feito em nível intermediário, nos setores da administração pública e na organização. Não obstante, trabalhando, são fundamentais as conexões e os vínculos com o nível macro. É necessário saber como se relacionam a política internacional, as metas do programa de desenvolvimento do milênio, as políticas públicas nacionais e regionais, e o plano nacional de desenvolvimento.

Com isso, o que se busca é o enfoque sistêmico por gestão de resultados no contexto da coisa pública. Ele menciona que a avaliação dos resultados não é apenas um fenômeno técnico, mas também apresenta dimensões políticas. No nível técnico, metodologias, instrumentos e medição são fundamentais, sobretudo porque, sem confiança na informação produzida, o trabalho se torna inútil.

"É preciso que existam parâmetros universais que permitam que as pessoas definam se o trabalho desenvolvido é confiável ou não. A dimensão política, entretanto, é fundamental também. Se nós reproduzirmos o processo mais perfeito de avaliação e, ao final, não usarmos as evidências produzidas, é como se nada tivesse sido feito", destacou a professora da NYU.

Na opinião de Ospina, esse é o quadro em que infelizmente se encontram muitos países da América Latina. A dimensão gerencial, fundamental para tornar a avaliação útil, é esquecida. Segundo ela: "é preciso haver uma mudança de cultura. É preciso que passemos a nos interessar pelos resultados, que devem ser orientados para a geração de valor público. E essa é a diferença em relação à discussão que tínhamos décadas atrás".

\section{Criação de valor público}

O quadro apresentado até aqui representa a situação na América Latina, desde as décadas de 1960 e 1970. Como mostrado no Quadro 3, entre 1980 e 1990 acontece uma mudança no enfoque de reforma do Estado. E também na forma de considerar a avaliação. À época, dada a crise econômica da região, houve um período de não Estado, de regularização, privatização e regulamentação. $\mathrm{O}$ foco era redução de gastos e legitimização das decisões do ponto de vista da eficiência.

Como explicou Sonia Ospina, na virada do século a tendência se tornou melhorar cada vez mais a máquina pública. A chave está no desempenho. A partir de tal ideia, a avaliação passa a ser considerada parte da administração pública, um instrumento fundamental e estratégico.

$\mathrm{Na}$ América Latina houve um aumento das cooperações internacionais. Elas exigem avaliações das políticas públicas e dos programas nas agências públicas, processo que também tem sido incentivado pelos processos de democratização. $\mathrm{O}$ que torna a prestação de contas fundamental.

Outro processo que demanda monitoramento e avaliação é a descentralização de atividades no setor público. Quando há envio de recursos para um nível inferior, novos processos de avaliação são demandados e necessários. Por fim, os processos de modernização do Estado também estão alimentando a ideia da gestão por resultados.

Por isso, a avaliação e monitoramento dos resultados atendem quatro tópicos: 
Quadro 3 - Três grandes "períodos" na avaliação do público (programas, políticas e reformas)

\begin{tabular}{|l|l|l|l|}
\hline Período & Condições & Enfoque da reforma & Enfoque da avaliação \\
\hline 60 e 70 & $\begin{array}{l}\text { Prosperidade } \\
\text { econômica }\end{array}$ & $\begin{array}{l}\text { Desenho e } \\
\text { implementação de } \\
\text { políticas; } \\
\text { reorganizações; } \\
\text { descentralização }\end{array}$ & $\begin{array}{l}\text { Avaliação de } \\
\text { programas }\end{array}$ \\
\hline 80 e 90 & $\begin{array}{l}\text { Crise }- \\
\text { retrocesso } \\
\text { econômico }\end{array}$ & $\begin{array}{l}\text { Desregulação; } \\
\text { privatização; redução } \\
\text { de custos }\end{array}$ & $\begin{array}{l}\text { legitimizar decisões } \\
\text { (eficiência) }\end{array}$ \\
\hline $\begin{array}{l}\text { Contração } \\
\text { moderada }- \\
\text { gerencialismo } \\
\text { (bom governo) }\end{array}$ & $\begin{array}{l}\text { Redução do tamanho; } \\
\text { fortalecimento } \\
\text { institucional; gestão } \\
\text { do desempenho }\end{array}$ & $\begin{array}{l}\text { - Fortalecer, melhorar } \\
\text { e legitimar o setor } \\
\text { público. Parte do ciclo } \\
\text { de gestão estratégica } \\
\text { (política pública) }\end{array}$ \\
\hline
\end{tabular}

- Melhorar as decisões políticas (planificação estratégica);

- Melhorar a distribuição de gastos (orçamento);

- Melhorar a gestão das instituições e programas (aprendizagem);

- Melhorar a prestação de contas (democracia).

$\mathrm{Na}$ prática, são poucos os sistemas dos países latino-americanos que conseguem desenvolver todos os quatro elementos como eixos para as atividades do Estado. Por isso, é importante pensar no contexto institucional em que a avaliação é feita. Faz-se necessário o diagnóstico dos objetivos: saber se o intuito é diminuir os gastos ou melhorar a prestação de contas, por exemplo.

$\mathrm{Na}$ Figura 1, vê-se os sistemas avaliados na última pesquisa. Fica claro que os países têm sistemas diferentes. Além disso, pode-se ver que se gasta muito tempo em programas de teste e pilotos antes de iniciar o programa formal.

Figura 1 - Evolução dos Sistemas

Chile - Colômbia - Costa Rica - Uruguai - México - Brasil - Brasil - Nicarágua Peru - Paraguai - Honduras

\begin{tabular}{|l|}
\hline Experimentação \\
\hline Sistema Formal \\
\hline
\end{tabular}

A partir dos quatro sistemas nacionais, que de alguma maneira foram precursores na América Latina no início da década de 1990 - Costa Rica, Uruguai, Colômbia e Chile -as pesquisas mostram que a maioria fala de avaliação e monitoramento, mas fazem apenas monitoramento. 
Apenas alguns países, no momento da pesquisa, estavam desenvolvendo esforços no sentido da avaliação, como Colômbia, México, Brasil, sendo esses ainda específicos. Contudo, a ênfase se encontra no monitoramento, o que pode ser problemático porque tal processo não leva à explicação de causas ou ao esclarecimento do processo como um todo.

Existem diferenças também em relação ao foco. Todos os sistemas avaliados têm um foco intermediário, estando esses programas baseados em agências. Por exemplo, na Colômbia todos eles tentaram se alavancar com o plano nacional de desenvolvimento. No caso do Uruguai, no nível micro o mais importante é a unidade em que se fazem os gastos.

Pode-se dizer que o Modelo Planejamento aparece, sobretudo, naqueles países em que há um plano nacional de desenvolvimento. O modelo está organizado em função de como se faz para que todas as atividades, todas as metas, todos os indicadores estejam inseridos na visão de longo prazo.

No segundo modelo, o de Orçamento, procuram-se casos racionalizados, como o exemplo do Uruguai em que os modelos e os sistemas estão identificados com as agências em que são usados.

O que os especialistas vem apontando, no entanto, é que o melhor modelo é uma combinação dos dois anteriores, isto é combinando planejamento nacional e gastos locais.

\section{A investigação comparada - o que se aprendeu}

Primeiramente, entre os muitos sistemas, é preciso entender em que medida se está institucionalizando uma capacidade de monitoramento e avaliação no setor público. Ospina buscou tal explicação em pesquisa que resultou na publicação
"Avaliação de resultados para uma gestão pública moderna e democrática: experiências latino-americanas", escrita por ela e Nubia Cunill e publicada pela Clad: Editora Texto. As autoras pesquisaram exemplos de sistemas em 12 países da América Latina.

"Por institucionalização entende-se informação comparada e disponível, valorizada pelos diversos atores presentes no cenário público e, portanto, usada na busca do bom governo. Ou seja, há um reconhecimento de que existe uma organização e de que todos os elementos contribuem para o fortalecimento da governança democrática e para o avanço dos objetivos do desenvolvimento", sintetizou.

$\mathrm{Na}$ América Latina o nível de institucionalização ainda é baixo em relação ao ideal. Vale fazer uma diferenciação. Nesta pesquisa tomou-se como foco os sistemas de avaliação e monitoramento, não os países. Foram estudados quatro aspectos: os antecedentes e a visão geral do sistema; a orientação funcional do sistema e a natureza de seus instrumentos; a coerência institucional; e uso da informação. Apresentam-se a seguir os principais achados:

- Foi constatado que sistemas mais antigos, como o caso da costa rica, são amadurecidos, sólidos. No entanto, mesmo esses sofrem ameaças por conta do contexto político. No exemplo costariquenho, o sistema sobreviveu a três mandatos de presidentes, mas no quarto perdeu o nível de institucionalização.

- Há poucos sistemas estáticos. A maior parte, inclusive os mais antigos, são sistemas dinâmicos, em constante reconfiguração. Isso significa, para as pesquisadoras, que não houve ainda uma institucionalização como se desejava. Para ela, a maior parte deles está em fase de reconfiguração ou redesenho. 
- Nos quatro sistemas, há o predominantemente político, em que se busca criar evidências para um nível macro, para ser levado à frente o conjunto de metas de desenvolvimento. O segundo é o predominantemente econômico, em que se procura melhorar a designação do gasto e fazê-lo de forma que tenhamos recursos mais bem usados.

- Existe um conjunto de sistemas que mistura o elemento econômico e político, o que significa que há esforços para combiná-los e talvez seja essa a preferência, pois leva em consideração a complexidade do processo.

- Curiosamente, para Sonia Ospina, encontram-se sistemas que são predominantemente sociais, o que constitui uma novidade, porque nesses casos há orientação direta e focada para avaliação e monitoramento dos programas sociais.

- A maior parte dos sistemas apresenta uma tendência à monofuncionalidade, apesar de na teoria eles se apresentarem como multifuncionais; e o desejo é de que eles sejam multifuncionais. "Existe uma contradição considerável e é importante pensar em trabalhá-la de alguma forma", aconselhou.

- Dimensão técnica: Existem avanços. Percebeu-se uma linguagem técnica importante, mas a informação continua sendo pouco usada. Muitos problemas são causados pela desconfiança em relação à procedência da informação.

- Dimensão política: O presidente e seus ministros são os mais importantes destinatários das avaliações, pois deles surgem as maiores demandas. Outros destinatários quase não usam os sistemas de avaliação e monitoramento. "Um elemento que merece destaque dentro da dimensão política é que a informação não produz impacto. Não existe um passo adiante. Não há prosseguimento", alertou a pesquisadora.
- Dimensão gerencial: Aponta-se que os resultados e a gestão por resultados fazem parte do diálogo do Estado. Mas existem problemas de transversalidade. Há muitas barreiras ainda difíceis de serem transpostas, em que as agências de controle não estão conversando com os sistemas nacionais.

$\mathrm{O}$ assunto mais importante da institucionalização da avaliação e monitoramento é o uso limitado da informação para a tomada de decisões. "O que constatamos é que as pessoas não confiam na informação, em parte porque, quando se pede a informação para alimentar os sistemas, a qualidade é baixa. Quando o sistema de avaliação e monitoramento é alimentado com os dados ruins, não se pode esperar bons resultados", disse.

Nos casos em que existem informações de qualidade, os diferentes usuários que poderiam se beneficiar com o acesso não as conhecem. Outro elemento interessante é que são gerados acréscimos de informação que podem ser inseridos no nível macro ou intermediário. Como há muitas escalas de dados, é preciso entender como essa informação pode ser esmiuçada, quebrada, lembrou Sonia Ospina.

\section{Lições e desafios}

"Primeiro, no nível mais geral, é importante nos servirmos de um pensamento sistêmico. É primordial também relacionar o técnico com o político e o gerencial, além de trabalhar com as expectativas, saber que avaliação e monitoramento não são uma panaceia", concluiu.

Para a pesquisadora, é preciso também distribuir a participação por todos os níveis. A liderança nos níveis mais altos é fundamental, principalmente se combinada ao enraizamento e ao compromisso daqueles que põem as ações em prática. 
"Termino a apresentação mencionando os grandes desafios que vejo neste momento com relação aos sistemas existentes. Em termos de dimensão técnica, é necessário assegurar a credibilidade da informação. É preciso capacitar tanto técnicos quanto gestores e funcionários de nível médio. Todos devem entender a necessidade da excelência. A conscientização deve ser geral", resumiu.

$\mathrm{Na}$ política, é preciso evitar o uso exclusivo dos presidentes e seus ministros, diz. Faz-se necessário que o congresso e os cidadãos tenham consciência dos sistemas de avaliação e monitoramento e que participem e façam uso dessa informação. Se, por um lado, a América Latina avançou muito, da mesma forma, a complexidade da implementação desses sistemas é enorme. "Para mim, depois de oito anos de trabalhos com sistemas, acredito que a maior lição é a necessidade de diálogo entre todos os atores envolvidos. Avaliadores, gestores, políticos e funcionários envolvidos no processo", finalizou. 
